\title{
Prevalence of nursing diagnosis of decreased cardiac output and the predictive value of defining characteristics in patients under evaluation for heart transplant
}

\author{
Lígia Neres Matos ${ }^{1}$ \\ Tereza Cristina Felippe Guimarães ${ }^{2}$ \\ Marcos Antônio Gomes Brandão ${ }^{3}$ \\ Deyse Conceição Santoro ${ }^{3}$
}

\begin{abstract}
The purposes of the study were to identify the prevalence of defining characteristics (DC) of decreased cardiac output (DCO) in patients with cardiac insufficiency under evaluation for heart transplantation, and to ascertain the likelihood of defining characteristics being predictive factors for the existence of reduction in cardiac output. Data was obtained by retrospective documental analysis of the clinical records of right-sided heart catheterizations in 38 patients between 2004 and 2009. The results showed that $71.1 \%$ of the patients had decreased cardiac output (measured by cardiac index). The majority of the NANDAInternational defining characteristics for DCO were more frequent in individuals with reduced cardiac index levels. The study emphasizes the odds ratio (OR) for increased Systemic Vascular Resistance of $O R=4.533$, of the third heart sound with $O R=3.429$ and the reduced ejection fraction with $\mathrm{OR}=2.850$. By obtaining the predictive values for the defining characteristics the study identifies them as diagnostic indicators of decreased cardiac output.
\end{abstract}

Descriptors: Heart Failure; Cardiac Output; Nursing Diagnosis.

${ }^{1} \mathrm{RN}$, Instituto Nacional de Cardiologia, Brazil.

2 PhD, Instituto Nacional de Cardiologia, Brazil.

${ }^{3}$ PhD, Adjunct Professor, Escola de Enfermagem Anna Nery, Universidade Federal do Rio de Janeiro, Brazil.

Corresponding Author:

Lígia Neres Matos

Rua Rodolfo Dantas, 85, Apto. 702

Bairro: Copacabana

CEP: 22020-040, Rio de Janeiro, RJ, Brasil

E-mail: ligianeresmatos@yahoo.com.br 


\title{
Prevalência do diagnóstico de enfermagem de débito cardíaco diminuído e valor preditivo das características definidoras em pacientes em avaliação para transplante cardíaco
}

Este estudo teve como propósito identificar a prevalência das características definidoras do débito cardíaco diminuído (DCD), em indivíduos com insuficiência cardíaca em avaliação para transplante cardíaco, e verificar a chance de as características definidoras serem fatores preditivos para a existência de diminuição no débito cardíaco. Os dados foram obtidos por análise documental retrospectiva de registros clínicos de cateterismo cardíaco direito em 38 pacientes, entre 2004 e 2009. Os resultados mostraram que $71,1 \%$ dos pacientes tiveram redução do débito cardíaco (medida pelo índice cardíaco). A maioria das características definidoras da NANDA-International para DCD foi mais frequente em indivíduos com redução do índice cardíaco. Destacam-se como razões de chances (odds ratio/OR) a resistência vascular sistêmica aumentada $O R=4,533$, a terceira bulha $O R=3,429$ e a fração de ejeção diminuída $O R=2,850$. Com a obtenção do valor preditivo das características definidoras, o estudo aponta as mesmas como indicativas do diagnóstico de débito cardíaco diminuído.

Descritores: Insuficiência Cardíaca; Débito Cardíaco; Diagnóstico de Enfermagem.

\section{Prevalencia del diagnóstico de enfermería de disminución del gasto cardíaco y valor predictivo de las características definidoras en pacientes en fase de evaluación para trasplante cardíaco}

\begin{abstract}
El estudio tiene como objetivos identificar la prevalencia de las características definitorias de la disminución del gasto cardíaco (DGC) en pacientes con insuficiencia cardíaca (IC) en evaluación para el trasplante de corazón y ver la probabilidad de las características definitorias sean factores predictivos de la existencia de una disminución del gasto cardíaco. Los datos se obtuvieron mediante el análisis documental retrospectivo de historias clínicas de cateterismo cordiaco derecho en 38 pacientes con insuficiencia cardíaca en la evaluación para el trasplante de corazón entre 2004 y 2009. Los resultados mostraron que el $71 \%$ de los pacientes habían reducido el gasto cardíaco (medido por el índice cardíaco). La mayoría de las características definitorias de la NANDA-International para el DGC fueron más frecuentes en individuos con índice cardíaco reducido. Los aspectos más destacados son la razón de probabilidad (odds ratio / OR) RVS mayor $\mathrm{OR}=4,533$, el tercer sonido $\mathrm{OR}=3,429$ y la disminución de la fracción de eyección $\mathrm{OR}=2,850$. Al obtener el valor predictivo de las características definitorias de estudio indica la importancia de las características para el diagnóstico de la disminución del gasto cardíaco.
\end{abstract}

Descriptores: Insuficiência Cardiaca; Gasto Cardiaco; Diagnóstico de Enfermería.

\section{Introduction}

Cardiac Insufficiency (CI), as a clinical syndrome, is characterized by the presence of cardiac dysfunction leading to a supply of blood which is inadequate to meet the tissues' metabolic needs, in the presence of normal venous return, or doing so with elevated filling pressures. In the face of such systemic repercussions, hemodynamic alterations are common among persons with cardiac insufficiency, such as - for example - an 
inadequate cardiac output (CO) response and elevations in pulmonary and venous systemic pressures.

$\mathrm{CI}$ is considered to be one of the growing epidemic problems in Brazil. According to data released by the Unified Health System/Ministry of Health, in 2007, CI was responsible for $2.6 \%$ of hospitalizations and for $6 \%$ of deaths in the Brazilian population.

In this epidemiological context, it becomes necessary for nurses to be able to make a judicious appraisal. The nature of nursing means that the nurse can engage with the care of the patient from outpatient treatment to participation in invasive hemodynamic procedures, with a greater degree of complexity.

The practice of nursing is notably underpinned by the nursing process, in five inter-related, interdependent and recurring stages: data collection, diagnosis, planning, implementation and evaluation ${ }^{(1)}$. The application of the process has promoted the use of standardized language for the principal practice situations: diagnosis, results and interventions ${ }^{(2)}$.

Nursing phenomena, when classified, function as organizers and possible accelerators for nursing clinical judgments, impacting on the improvement in reliability of the conclusions and on the recuperation or survival of individuals.

Nursing diagnosis plays a crucial role in nursing practice, being capable of expressing the patients' care needs(3). In accordance with this characteristic, the diagnosis assumes a central character in communicating the judgment that the nurse develops from human responses.

Internationally, at the beginning of the 1970s, interest in the use of standardized nursing language became more deeply-rooted as NANDA's classification for nursing diagnoses developed. The changes required in taxonomy led to the proposition, from 2000 on, for Taxonomy II as a model for the organization of nursing diagnoses $^{(3)}$.

The definition of nursing diagnosis approved at the $9^{\text {th }}$ NANDA Conference and adopted for study presents nursing diagnosis as a clinical judgment to the responses of an individual, a family or a community to problems of health or vital processes, whether real or potential. The nursing diagnosis constitutes the base for a selection of nursing interventions aimed at achieving the results for which the nurse is responsible.

Nursing diagnoses may be of the following types: actual, risk, possible wellbeing, and syndrome. Their components are: title (name or label), definition (a clear and precise description), defining characteristics (indications and observable inferences), and related factors (factors which can show a standardized relation to the diagnosis $)^{(4)}$. The 'decreased cardiac output', an actual diagnosis, is characterized by the heart pumping a quantity of blood which is insufficient to meet the body's metabolic needs.

The improvement of nursing diagnoses depends on refining the identification of observable characteristics which can guide the more precise understanding of a given phenomenon, bearing in mind that human judgment has an inherent imprecision influenced by beliefs, ethnicity, culture, philosophical tenets and implicit and explicit values ${ }^{(5)}$.

In order to make the search for diagnostic validity more tenable, when possible, it is desirable that standardized tests should be carried out, capable of serving as a base for the evaluation of diagnostic judgments' accuracy; the so-called 'gold standard'. In the context of decreased cardiac output, the gold standard would represent the value of cardiac output as measured by appropriate equipment (invasive or noninvasive).

Although there is a growing quantity of validation research, decreased cardiac output in cardiac insufficiency continues to be an under-explored area ${ }^{(5)}$. Further, diagnostic studies in situations in which a gold standard can be identified are extremely rare in nursing, although they are relevant to refining and constructing the validity of diagnostic language. It should be understood that this is one of the justifying factors proposed for the study.

The problematic relationship between the existence of defining characteristics and measurement of cardiac output leads to the following objectives: to identify the prevalence of defining characteristics for decreased cardiac output (DCO) in individuals with cardiac insufficiency under evaluation for heart transplant, and to ascertain the likelihood of defining characteristics being predictive factors for the existence of reduction in cardiac output.

This study contributes to the clinical validation of nursing diagnoses, a strategy which is essential for the development of knowledge about nursing diagnoses.

\section{Methods}

The study is cross-sectional with retrospective documental analysis and a descriptive character. The material for analysis was the relevant sections of the clinical records of 38 patients with CI under evaluation for heart transplant at the National Institute of Cardiology, from 2004 - 2009. 
The study includes adults who had undergone Right-sided Cardiac Catheterization (RCC) using a flowdirected Swan-Ganz pulmonary artery catheter, with continuous cardiac output monitoring with a Vigilance Monitor ${ }^{\circledR}$. In the institution, RCC is an examination for evaluation of candidates for heart transplantation. Moreover, during the examination, arterial pressure was monitored non-invasively, so as to obtain the systolic pressure, diastolic pressure, average pressure and pulse oximetry, with regular checking every three minutes.

The procedure was carried out in the Surgical Cardiac Intensive Care Unit at the National Institute of Cardiology, by a medical professional and a nurse, when patients were considered candidates for cardiac transplantation. The clinical findings mentioned above were documented in the researchers' own instrument (RCC report) and in the medical records, which served as the researchers' material for analysis.

For the document search, the defining characteristics identified by NANDA as possible causes of decreased cardiac output were selected ${ }^{(4)}$. It was decided that the first option should be to search for entries which form part of the research instrument for RCC, largely because of the greater reliability of the data collected. In a complementary fashion, the medical records were analyzed to confirm the findings recorded in the report.

For content analysis of the texts, the following defining characteristics related to the invasive method were selected; decreased cardiac output, reduced cardiac index, increased or decreased pulmonary and systemic vascular resistance, and increased or decreased central venous pressure and pulmonary capillary pressure. For non-invasive methods, bradycardia, tachycardia, dyspnea, reduced ejection fraction and the sounds S3 and $\mathrm{S} 4^{(4)}$ were chosen.

In delineating the study, the presence of defining characteristics was considered to be an indicator for tests (or assessment), and the measuring of cardiac rate to be the 'gold standard' (outcome).

The magnitude of occurrence of a DC is associated with a greater or lesser prediction of its diagnosis, which justifies the investigations into its prevalence.

In this study, the 'gold standard' for decreased cardiac output (outcome) was expressed in a measurement of cardiac index (CI) less than or equal to $2.51 / \mathrm{min} / \mathrm{m}^{2}$. On the other hand, one may also verify the behavior of defining characteristics in circumstances in which the cardiac index indicates normality. The possibility of substantiating the gold standard and correlating it with clinical evidence dramatically increases the reliability of the association between the predictor variable (the observable defining characteristic) and the outcome (the nursing diagnosis developed).

The selection of cardiac index as indicative of 'gold standard' - rather than the nominal measurement of output - is based on a clinical justification. Cardiac output increases proportional to the individual's body surface area, which calls for the measurement to be adjusted according to body surface area. The cardiac index, expressed by cardiac output per square meter of body surface area (cardiac output divided by body surface area) is considered the most important indicator for the functioning of the cardiovascular system.

For data processing and analysis, the program SPSS $^{\circledR}$ (version 13.0) was used.

The prevalence of defining characteristics was calculated and represented in percentage and absolute terms.

The odds ratio for the defining characteristics was calculated. A defining characteristic's odds ratio indicated its likelihood of being present in individuals with decreased cardiac output (CI less than $2.5 \mathrm{l} / \mathrm{min}$ / $\mathrm{m}^{2}$ ) against its likelihood of being present in normal individuals. Odds greater than 1.0 indicated a greater probability of it being present in individuals with decreased cardiac output than in those with normal output.

This test was relevant to demonstrate the predictive value of a given defining characteristic, improving the possibilities of diagnostic inference.

A confidence interval of $95 \%$ was adopted. The chisquare test was utilized for significance and the value of $p<0.005$ was considered statistically significant.

The study met the ethical requirements made and was approved by the National Institute of Cardiology/ Ministry of Health's Ethics in Research Commission, report 0246/10.07.09.

\section{Results}

The material for analysis, referring to 38 adult individuals under evaluation for cardiac transplant who underwent right-sided cardiac catheterization between 2004 and 2009 at the National Institute of Cardiology/ Ministry of Health/Rio de Janeiro, indicated that $71 \%$ of the patients were female, $60.5 \%$ were Caucasian, and that their average age was 47 . In $92.1 \%$ of the cases, the procedure was carried out in the Surgical Cardiac Intensive Care Unit, via right internal jugular vein puncture. 
Clinical and demographic characterization of the individuals was carried out based on the conditions of the cardiac index, so as to highlight possible predominances in the characteristics categories (Table 1 ). There was no statistically significant difference between the categories of sex $(p=0.4010)$, race $(p=0.884)$ or underlying disease $(0.104)$ when related to decreased cardiac index.

Table 1 - Clinical-demographic characteristics and cardiac index

\begin{tabular}{|c|c|c|c|c|c|c|c|}
\hline \multirow{3}{*}{ Clinical-demographic characteristics } & \multicolumn{4}{|c|}{ Cardiac Index (Cl) } & \multirow{2}{*}{\multicolumn{2}{|c|}{$\begin{array}{c}\text { Total of } \\
\text { characteristics }\end{array}$}} & \multirow{3}{*}{$\mathbf{p}$} \\
\hline & \multicolumn{2}{|c|}{$\mathrm{Cl} \leq 2.5$} & \multicolumn{2}{|c|}{$\mathrm{Cl}>2.5$} & & & \\
\hline & $\mathbf{n}$ & $\%$ & $\mathbf{n}$ & $\%$ & $\mathbf{n}$ & $\%$ & \\
\hline \multicolumn{8}{|l|}{ Skin Color } \\
\hline White & 15 & 65.2 & 8 & 34.8 & 23 & 60.5 & 0.401 \\
\hline Black & 8 & 88.9 & 1 & 11.1 & 9 & 23.7 & \\
\hline Mixed & 4 & 66.7 & 2 & 33.3 & 6 & 15.8 & \\
\hline \multicolumn{8}{|l|}{ Sex } \\
\hline Male & 8 & 72.7 & 3 & 27.3 & 11 & 28.9 & 0.884 \\
\hline Female & 19 & 70.4 & 8 & 29.6 & 27 & 71.1 & \\
\hline \multicolumn{8}{|l|}{ Underlying disease } \\
\hline CMP chagasic & 6 & 85.7 & 1 & 14.3 & 7 & 18.4 & 0.104 \\
\hline CMP idiopathic dilated & 9 & 75 & 3 & 25 & 12 & 31.6 & \\
\hline CMP dilated-myocarditis & 2 & 100 & 0 & 0 & 2 & 5.3 & \\
\hline CMP hypertrophic & 1 & 100 & 0 & 0 & 1 & 2.6 & \\
\hline CMP ischemic & 7 & 63.6 & 4 & 36.7 & 11 & 28.9 & \\
\hline CMP Peripartum & 2 & 100 & 0 & 0 & 2 & 5.3 & \\
\hline Valvulopathy & 0 & 0 & 3 & 100 & 3 & 7.9 & \\
\hline \multicolumn{8}{|l|}{ Comorbidities } \\
\hline Diabetes Mellitus & 1 & 20 & 4 & 80 & 5 & 13.2 & \\
\hline Nephropathy & 3 & 75 & 1 & 25 & 4 & 10.5 & \\
\hline Hepatopathy & 2 & 100 & 0 & 0 & 2 & 5.3 & \\
\hline Systemic Arterial Hypertension & 5 & 55.6 & 4 & 44.4 & 9 & 23.7 & \\
\hline Pulmonary Hypertension & 7 & 100 & 0 & 0 & 7 & 18.4 & \\
\hline Dyslipidemia & 5 & 71.4 & 2 & 28.6 & 7 & 18.4 & \\
\hline Obesity & 1 & 100 & 0 & 0 & 1 & 2.6 & \\
\hline Total & 27 & 71.1 & 11 & 28.9 & 38 & 100 & \\
\hline
\end{tabular}

Unit of Cardiac Index (CI): lit $/ \mathrm{min} / \mathrm{m}^{2}$

Table 1 indicates the greatest prevalence of cardiomyopathies in the sample: idiopathic dilated $(31.6 \%)$, ischemic $(28.9 \%)$, and chagasic (18.4\%). Among comorbidities, chronic diseases dominate; systemic arterial hypertension (23.7\%), dyslipidemia (18.4\%) and diabetes mellitus (13.2\%).

Considering the sample as a whole, it was ascertained that $71.1 \%$ of the individuals presented reduced measurement in cardiac index $(n=27)$ and
28.9\% showed normal values. This indicator was used to permit correlations with the defining characteristics, shown below.

Table 2 shows the prevalence of defining characteristics among individuals with decreased cardiac index and individuals with normal values. The third column includes the values and the percentages of occurrence of each characteristic, considering the 38 individuals. 
Table 2 - Defining characteristics organized by categories, and reduced cardiac index $\left(<2.5 \mathrm{l} / \mathrm{min} / \mathrm{m}^{2}\right)$

\begin{tabular}{|c|c|c|c|c|c|c|c|}
\hline \multirow{3}{*}{ Defining characteristics by category } & \multicolumn{4}{|c|}{ Reduced cardiac index } & \multirow{2}{*}{\multicolumn{2}{|c|}{$\begin{array}{l}\text { Total of characteristics } \\
\text { in the individuals }\end{array}$}} & \multirow{3}{*}{$\mathbf{p}$} \\
\hline & \multicolumn{2}{|c|}{ Yes } & \multicolumn{2}{|c|}{ No } & & & \\
\hline & $\mathbf{n}$ & $\%$ & $\mathbf{n}$ & $\%$ & $\mathbf{n}$ & $\%$ & \\
\hline \multicolumn{8}{|l|}{ 1. Altered cardiac frequency or rhythm } \\
\hline Bradycardia & 3 & 75 & 1 & 25 & 4 & 10.5 & 0.854 \\
\hline Tachycardia & 3 & 100 & 0 & 0 & 3 & 7.8 & 0.749 \\
\hline \multicolumn{8}{|l|}{ 2. Altered preload } \\
\hline Edema & 2 & 66.7 & 1 & 33.3 & 3 & 7.8 & 0.861 \\
\hline PAOP - increased & 16 & 64 & 9 & 36 & 25 & 65.7 & 0.184 \\
\hline PAOP - reduced & 0 & 0 & 1 & 100 & 1 & 2.6 & 0.112 \\
\hline CVP - increased & 6 & 66.7 & 3 & 33.3 & 9 & 236 & 0.74 \\
\hline CVP - reduced & 4 & 66.7 & 2 & 33.3 & 6 & 15.7 & 0.067 \\
\hline \multicolumn{8}{|l|}{ 3. Altered afterload } \\
\hline PVR - increased & 12 & 100 & 0 & 0 & 12 & 31.5 & $0.008^{*}$ \\
\hline PVR - reduced & 13 & 56.5 & 10 & 43.5 & 23 & 60.5 & $0.014^{*}$ \\
\hline SVR - increased & 17 & 85 & 3 & 15 & 20 & 52.6 & $0.046^{*}$ \\
\hline SVR - reduced & 0 & 0 & 2 & 100 & 2 & 5.2 & $0.023^{*}$ \\
\hline \multicolumn{8}{|l|}{ 4. Altered contratility } \\
\hline EF - reduced & 19 & 79.2 & 5 & 20.8 & 24 & 63.1 & 0.149 \\
\hline S3 & 20 & 80 & 5 & 20 & 25 & 65.7 & 0.092 \\
\hline Total & 27 & 71.1 & 11 & 28.9 & 38 & 100 & \\
\hline
\end{tabular}

There were no cases of dyspnea or S4

$*$ Statistically significant $p$ values $(p<0.05)$

PAOP - Pulmonary Artery Occlusion Pressure; CVP - Central Venous Pressure; PVR - Pulmonary Vascular Resistance; SVR - Systemic Vascular Resistance; EF - Ejection Fraction; S3 - Third heart sound.

Table 2 expresses the greatest total prevalence (in the number of subjects) of the defining characteristics in findings about altered cardiac contractility: ejection fraction (63.1\%) and third heart sound (S3). The categories of altered afterload; reduced pulmonary vascular resistance $(60.5 \%)$, increased systemic vascular resistance $(52.6 \%)$ and increased pulmonary vascular resistance $(31.5 \%)$. In the altered preload's defining characteristics category, increased pulmonary artery occlusion pressure is the most prevalent.

Remaining with Table 2, on relating frequencies to the decrease in the cardiac index, the higher occurrence percentages for the group with CI less than $2.5 \mathrm{l} / \mathrm{min} /$ $\mathrm{m}^{2}$ were for the characteristics previously identified in the total percentage, and also for: tachycardia (100\%), bradycardia $(75 \%)$, edema $(66.7 \%)$ and increased or decreased central venous pressure (both with 66.7\%).

Decreased systemic vascular resistance and decreased pulmonary artery occlusion pressure, on the contrary, were only found in individuals with normal cardiac index.

The odds ratio (OR) was applied in order to investigate the chances of relationship between the defining characteristics and the outcome measured (the cardiac index). From the point of view of statistical significance, the following defining characteristics related to afterload were significant: afterload with increased PVR $(p=0.008)$, afterload with decreased PVR $(p=0.014)$, afterload with increased SVR $(p=0.046)$ and afterload with decreased SVR $(p=0.023)$. However, in the sample, the presence of defining characteristics such as increased SVR OR=4,533 (0,972-21,141), third heart sound $\mathrm{OR}=3,429(0,791-14,853)$ and decreased ejection fraction $\mathrm{OR}=2,850(0,671-12,101)$ were strongly associated with a reduced cardiac index (Table 3). 
Table 3 - Defining characteristics organized by category and Odds Ratio (OR)

\begin{tabular}{lc}
\hline \multicolumn{1}{c}{ Defining Characteristics by category } & Odds Ratio (IC 95\%) \\
\hline 1. Altered cardiac frequency/rhythm & \\
Bradycardia & $1.250(0.116-13.511)$ \\
2. Altered Preload & \\
Edema & $0.800(0.65-9.844)$ \\
PAOP increased & $0.323(0.58-1.794)$ \\
CVP increased & $0.762(0.153-3.802)$ \\
CVP decreased & $0.783(0.171-5.048)$ \\
3. Altered afterload & \\
PVR decreased & $0.093(0.010-0.830)$ \\
SVR increased & $4.533(0.972-21.141)$ \\
4. Altered Contractility & \\
EF decreased & $2.850(0.671-12.101)$ \\
S3 & $3.429(0.791-14.853)$ \\
\hline PAOP- Pulmonary Capillary Occlusion Pressure & \\
CVP - Central Venous Pressure & \\
SVR - Systemic Vascular Resistance & \\
EF - Ejection Fraction & \\
S3 - Third heart sound &
\end{tabular}

\section{Discussion}

It is understood that the results must be evaluated from the perspective of nursing clinical practice. They may be categorized into items that require evaluation with clinical examination technologies (heart sounds, edema, cardiac frequency) and those which require invasive monitoring (measurements related to preload, afterload and cardiac contractility).

As far as the characterizing elements of the subjects are concerned, it must be emphasized that, although the predominance of the female group was not configured as being significant in the statistical model, one must consider the clinical significance of the findings when seeking to make generalizations for both sexes. In a study carried out in Brazil, cardiac insufficiency was more related to the male sex $(60.46 \% \text { of cases })^{(6)}$.

The results of the study outlined in this article align with the findings of the above-mentioned study, which also indicates an important frequency of myocardiopathies in situations of congestive heart failure (CHF).

Among the comorbidities, the high co-occurrence of nephropathy, hepatopathy, pulmonary hypertension and dyslipidemia in the individuals with a lowered cardiac index may be a facilitating factor in identifying the nursing diagnosis of decreased cardiac output.

In a study which evaluated the peak cardiac index of 19 patients with $\mathrm{CHF}$, all the cases of functional class III had a response of moderately or markedly reduced cardiac output ${ }^{(7)}$. Such findings converge with those of this research.

The high occurrence of the defining characteristics of decreased cardiac output in individuals who really had a low cardiac index reinforces the use of nursing diagnoses in the profession's clinical practice.

In conditions similar to those of the study, one can presume the value of a search by defining characteristics, and especially by those which were more prevalent in the circumstances of reduction in the measurement of cardiac index, in order to know: ejection fraction, third heart sound, decreased pulmonary vascular resistance, increased systemic vascular resistance, increased pulmonary vascular resistance, increased pulmonary artery occlusion pressure, tachycardia, bradycardia, increased central venous pressure, and decreased central venous pressure.

On the other hand, the study did not substantiate decreased systemic vascular resistance and decreased pulmonary artery occlusion pressure in situations of decreased cardiac index. Nevertheless, one must consider the reduced number of such occurrences in the sample, a fact which tends to weaken firmer assertions concerning validity and generalization.

In the clinical nursing evaluation, the findings which indicate a higher probability $(3,429)$ of the third heart sound being associated with decreased cardiac output are of value for the physical examination carried out by the nurse. This becomes more relevant in comparison with the study carried out to validate DCO in patients with cardiac insufficiency ${ }^{(8)}$, in which it was ascertained that in the convergence of the results, the occurrence of the third heart sound was not considered as reliable by experts in the quality of the determining variables for decreased cardiac output. Fatigue, dyspnea, edema and orthopnea were considered to be the most determinant factors.

However, studies which have investigated the defining characteristics demonstrate heterogeneity between methods and levels of evidence, but lack some variables: age, sex and sample number, which make the carrying-out of meta-analysis impossible. Such characteristics indicate the difficulty of comparing the present findings with those of other studies.

Further, it has to be added that the research subjects had been clinically stabilized prior to monitoring, even though they were classified as being in the last two functional classes. Thus, it can be affirmed that the manifestations are essentially present in the natural evolution of the heart problem, and do not typify acute 
manifestations of cardiac decompensation. This being so, it is presumed that the presence of the third heart sound should not be underestimated in the delineation of the nursing diagnosis hypothesis for DCO among patients with $\mathrm{CHF}$.

Unlike the study mentioned, developed with experts $^{(7)}$, the present research did not support the evidence that edema is associated with decreased cardiac index in patients with $\mathrm{CHF}$, which weakens the predictive power of edema in DCO.

In a study carried out on 49 subjects, edema was verified in equal occurrence in individuals with both decreased and normal cardiac index in situations following cardiac surgery ${ }^{(10)}$. This corroborates assertions about the low predictive reliability of investigation into edema to decide on the presence of decreased cardiac output.

Even so, one has to reflect on the nature of the circumstances of the diagnostic investigation. It has to be taken into account that, in clinical practice, the nurses deal with the nursing diagnosis as an entity with both a complex nature and subjective indicators, which makes it difficult to produce a more precise and objective correlational view, as may be verified here by the measurement of the cardiac index. Although the imprecision of clinical judgment is a reality that is impossible to resolve as a whole, one has to proceed to clinical judgments even with the existence of the risk of errors.

The OR of 1.250 for bradycardia means that this too can figure among the defining characteristics and should receive the attention of the nurse when considering the diagnosis of decreased cardiac output.

In the category of findings obtained by invasive technology, the results concerning increased vascular resistance (4.533) and decreased ejection fraction (2.850) support the notion that these defining characteristics noted in Taxonomy II may be used as predictors for decreased cardiac output with greater reliability, due to their higher odds ratio.

The defining characteristics related to the pulmonary artery catheter - for example, cardiac output, alteration of pulmonary artery pressure, pulmonary artery occlusion pressure, cardiac index, venous oxygen saturation, systemic and pulmonary vascular resistance - did not show statistical relevance in a review study ${ }^{(9)}$.

The defining characteristics obtained by invasive means are measurements that converge on the 'gold standard' (the cardiac index) and in circumstances in which they may be obtained should not be looked down on. Thus, the verification of the odds greater than 1.0 supports the validation of the characteristics described in NANDA's Taxonomy II.

\section{Conclusions}

The study allowed the demonstration of higher frequencies for the majority of the defining characteristics noted by NANDA in individuals with decreased cardiac index. In the non-invasive category, the third heart sound and bradycardia were considered to have a greater probability of predictive value. In the invasive category, increased pulmonary vascular resistance, increased systemic vascular resistance, decreased pulmonary vascular resistance and decreased ejection fraction were considered to have a greater probability of predictive value.

The comparison of clinical and parametric evidence with measurement of outcome (decreased cardiac index) confirmed the value of evaluation and diagnostic presumption for the majority of the defining characteristics of DCO. Such an aspect can contribute to the validation of the nursing diagnosis, with consequences that are favourable to professional practice.

By recognizing the limits of generalizing from the study's results - due to the number of cases evaluated - it seems reasonable to consider replicating it in similar studies with clients in similar situations and with cardio-vascular comorbidities which are not $\mathrm{CHF}$, to verify specific qualities which can qualify the nursing clinical judgment. Also, it is recommended that nurses' diagnostic judgments be compared with the cardiac index test, such that their accuracy may be measured.

\section{References}

1. Resolução COFEN-358/2009 (BR). Dispõe sobre a Sistematização da Assistência de Enfermagem e a implementação do Processo de Enfermagem em ambientes, públicos ou privados, em que ocorre o cuidado profissional de Enfermagem, e dá outras providências. [Internet]. 15 out 2009. Disponível em: http://site.portalcofen.gov.br/node/4384

2. Barros ALBL. Classificação de Diagnóstico e Intervenção de Enfermagem: NANDA-NIC. Acta Paul Enferm. 2009;22(esp 70 anos):864-7. 
3. Braga CG, Cruz DALM. The Taxonomy II proposed by the North American Nursing Diagnosis Association ( NANDA) . Rev. Latino-Am. Enfermagem. [periódico na Internet]. 2003 Mar [acesso 5 dez 2011]; 11(2):240-4. Disponível em: http://www. scielo.br/scielo.php?script=sci_arttext\&pid=S01041692003000200016\&lng=en. http://dx.doi. org/10.1590/S0104-11692003000200016.

4. NANDA. (International). Diagnósticos de Enfermagem da NANDA: definições e classificação 2007-2008 Porto Alegre (RS): Artmed; 2008.

5. Matos FGOA, Cruz DALM. Construção de instrumento para avaliar a acurácia diagnóstica. Rev Esc Enferm USP. 2009; [acesso 4 dez 2011]; 43(esp):108897. Disponível em http://www.scielo.br/pdf/reeusp/ v43nspe/a13v43ns.pdf.

6. Barreto AC, Nobre MRC, Wajngarten M, Canesin MF, Ballas D, Serro-Azul JB. Insuficiência Cardíaca em Grande Hospital Terciário de São Paulo. Arq Bras Cardiol. 1998;71(1):15-20.

7. Yamabe H, Itoh K, Yasaka Y, Takata T, Yokoyama M. The role of cardiac output response in blood flow distribution during exercise in patients with chronic heart failure. Eur Heart J. [periódico na Internet]. 1995; [acesso 15 fev 2011]; 16(7):951-60. Disponível em: http://eurheartj. oxfordjournals.org/content/16/7/951.abstract

8. Martins Q, Aliti G, Rabelo E. Decreased Cardiac Output: Clinical Validation in Patients With Decompensated Heart Failure Decreased Cardiac Output: Clinical Validation in Patients With Decompensated Heart Failure. Int J Nurs Terminol Classif. 2010 Out; [acesso 15 fev 2011]; 21(4):156-65. Disponível em: http://onlinelibrary.wiley. com/doi/10.1111/j.1744-618X.2010.01161.x/abstract

9. Souza V, Zeitoun SS, Barros ALBL. Débito Cardíaco Diminuído : Revisão sistemática das Características Definidoras. Acta Paul Enferm. [periódico na Internet]. 2011 [acesso $13 \mathrm{dez} 2011$ ]; 24(1): 114-9. Disponível em: http://www.scielo.br/scielo.php?script=sci_ arttext\&pid =S0103-1002011000100017\&Ing=en. http://dx.doi.org/10.1590/S0103-21002011000100017 10. Oliva APV, Cruz DALM. Decreased Cardiac Output: validation with postoperative heart surgery patients. Dimensions Crit Care Nurs. 2003;22(1):39-44. 